\title{
How Sustainability Ratings Might Deter “Greenwashing”: A Closer Look at Ethical Corporate Communication
}

\begin{abstract}
Of the many ethical corporate marketing practices, many firms use corporate social responsibility (CSR) communication to enhance their corporate image. Yet consumers, overwhelmed by these more or less well-founded CSR claims often have trouble identifying truly responsible firms. This confusion encourages "greenwashing" and may make CSR initiatives less effective. On the basis of attribution theory, this study investigates the role of independent sustainability ratings on consumers' responses to companies' CSR communication. Experimental results indicate the negative effect of a poor sustainability rating for corporate brand evaluations in the case of CSR communication, because consumers infer less intrinsic motives by the brand. Sustainability ratings thus could act to deter "greenwashing" and encourage virtuous firms to persevere in their CSR practices.
\end{abstract}

KEY WORDS: ethical corporate marketing, CSR communication, attribution theory, sustainability ratings. 


\section{INTRODUCTION}

Broadly defined, corporate social responsibility (CSR) attempts to achieve commercial success in ways that honour ethical values and respect people, communities, and the natural environment (Bhattacharya and Sen, 2004). The study of CSR generally appears within investigations of general stakeholder theory (Clarkson, 1995; Donaldson and Preston, 1995), but consumers largely were ignored as stakeholders before marketing researchers started to examine their responses to firms' respect or violation of social principles. Beyond consumers' responses to CSR activities, the question of their reactions to ethical corporate marketing and, more specifically, to CSR communication, though relatively recent in marketing research (Maignan and Ferrell, 2004; Swaen and Vanhamme, 2005; Morsing, 2006; Du et al., 2010), has gained greater importance, because CSR communication expenses have grown to become the third-largest budget item for corporate communication departments in large companies (Hutton et al., 2001).

CSR corporate communication pertains to communicated corporate identity and is supposed to play a crucial role in the formation of ethical corporate perceptions (Balmer et al., 2007; Fukukawa et al., 2007), and social legitimacy (Wæraas and Ihlen, 2009; Vanhamme and Grobben, 2009). However, the profusion of CSR claims, whether well-founded or not, creates difficulties for consumers who attempt to distinguish between truly virtuous firms and firms taking opportunistic advantage of sustainable development trends or, otherwise stated, between reputation and rhetoric (Fukukawa et al., 2007; Bernstein, 2009). In response, a strong movement denounces "greenwashing" (Bradford, 2007), defined as tactics that mislead "consumers regarding the environmental practices of a company or the environmental benefits of a product or service" (www.terrachoice.com). In such conditions, the potential benefits of CSR communication for corporate brand evaluation may be questionable, even for truly responsible companies. The situation also could lead to a prisoner's dilemma, in which 
responsible firms would benefit if they halted their responsible practices but still communicated about those practices. This dilemma raises an important societal research question: How can society regulate CSR communication practices to deter "greenwashing" and encourage virtuous companies in their initiatives?

Within the context of a growing number of independent sources of information, this research specifically addresses questions about the potential influence of sustainability ratings on consumers' responses to CSR communication. To reach this objective, we investigate how consumers decode CSR communication in light of sustainability ratings, for which attribution theory offers a particularly well-suited option (Sjovall and Talk, 2004; Van de Ven, 2008). In the next section, we therefore summarise important concepts from ethical corporate marketing literature, with particular attention to distinguishing controllable corporate communication from non-controllable corporate information. Then we draw on attribution theory to derive hypotheses about how a good or poor sustainability rating might influence consumers' attitude making process and CSR communication's efficiency through motive attributions. To test the hypotheses, we turn to an experiment with a sample of adult consumers. We conclude with a discussion of the theoretical and societal implications of our findings for sustainability ratings and the effects of CSR communication on corporate brand building.

\section{LITERATURE REVIEW}

\section{CSR communication and ethical corporate marketing}

To clarify the corporate marketing paradigm, Balmer and Greyser $(2003,2007)$ propose an integrative model of corporate identity composed of five distinct facets. The communicated identity facet-or what the company communicates to its shareholders-has particular importance for this research, because communicated identity serves as a nexus between the company's identity and image (Gray and Balmer, 1998), which reflects the "immediate 
mental picture an individual has of an organization" (Balmer, 2009, p.558). Furthermore, Fukukawa and colleagues (2007) insist that corporate identity ("what we really are") should be congruent with communication ("what we say we are"). Therefore, when studying the effect of ethical corporate marketing on corporate image, the investigation of corporate communications about ethical subjects should be a priority.

As an aspect of corporate communication, CSR communication "is designed and distributed by the company itself about its CSR efforts" (Morsing, 2006, p.171) and can reflect three potential approaches (Van de Ven, 2008). The reputation management approach focuses "on the basic requirements of conducting a responsible business to obtain and maintain a license to operate from society" (Van de Ven, 2008, p.345) and implies no explicit CSR communication. The second approach, building a virtuous corporate brand, means making an "explicit promise to the stakeholders and the general public that the corporation excels with respect to their CSR endeavours" (Van de Ven, 2008, p.345), which clearly suggests CSR communication. In this sense, two communication instruments are available (Van de Ven, 2008): corporate communication instruments (e.g., CSR reporting, publication of ethical codes, Web sites) and marketing communication instruments (e.g., advertising, sponsoring, direct marketing and promotions, public relations). The latter, which can be overly salient (Sjovall and Talk, 2004), are riskier and therefore remain less common, despite some recent rapid growth. For example, in France in 2008, $6 \%$ of mass media advertisements included messages about company actions to protect the environment, a six-fold increase compared with 2006 (ARPP, 2009). The third, ethical product differentiation approach means "differentiating a certain product or service on the basis of an environmental or social quality" (Van de Ven, 2008, p.348). In this case, CSR efforts constitute the heart of the brand positioning (e.g., The Body Shop, Natura Brasil), which makes CSR communications natural and inevitable. 
Managers have long followed a simple principle: Do good and let others talk about it (Kotler and Lee, 2005). Yet the use of CSR communication is growing, in small- and medium-sized enterprises as in multinational corporations (Nielsen and Thomsen, 2009), in transition markets as in mature economies (Grbac and Loncaric, 2009; Alon et al. 2010). The reason is that CSR communication provides a corporate marketing tool that can build a strong corporate image and reputation (Balmer, 1998, 2009; Gray and Balmer, 1998; Hoeffler and Keller, 2002; Balmer and Greyser, 2007) and achieve social legitimacy (Wæraas and Ihlen, 2009; Vanhamme and Grobben, 2009). However, we know little about how a central group of stakeholders, namely, consumers, actually respond to it.

\section{Controversial effects of CSR communication on consumers}

Most empirical studies indicate a strong negative impact of a company's alleged irresponsible acts (e.g., child labour, human rights violations, air and water pollution) on attitudes toward the firm (Murray and Vogel, 1997; Folkes and Kamins, 1999), as well as on attitudes toward the product and purchase intentions (Murray and Vogel, 1997; Swaen and Vanhamme, 2004, 2005). Mohr and Webb (2005) demonstrate the asymmetric impact of societal practices on consumers' perceptions, as suggested by Creyer and Ross (1997). Strong CSR performance positively influences consumers' attitudes toward the firm and purchase intentions, whereas poor performance damages them even more. Although the negative impact of irresponsible acts is unambiguous, the positive effect of good societal performances is more controversial (Brown and Dacin, 1997; Swaen and Vanhamme, 2004; Mohr and Webb, 2005). The main weakness of these research works is that they rarely take into account the "communication" theoretical framework, meaning they do not systematically question the expression of the message, the credibility of the source, or the medium used (Du et al., 2010).

To date, the specific effects of proactive CSR communication have received little attention in marketing research. Schlegelmilch and Pollach (2005) generally discuss the perils 
and opportunities of communicating corporate ethics. Other works focus on the effect of previous CSR communication in the case of a crisis (Swaen and Vanhamme, 2004; Vanhamme and Grobben, 2009). Benoit-Moreau and Parguel (2010) also demonstrate a positive impact of CSR communication on perceived corporate brand equity, depending on the perceived congruency between the company and the cause supported: The more congruent the engagement, the more efficient is the communication. In the end, Du and colleagues (2010) present a comprehensive conceptual framework of CSR communication.

The investigation of consumers' responses to explicit CSR communication is even more crucial in an actual context, because the profusion of CSR claims has prompted a movement that denounces those advertising agencies that encourage "greenwashing" (Bradford, 2007). Consumers' scepticism toward firms that take opportunistic advantage of sustainable development trends thus is growing (Pomering and Johnson, 2009; Du et al., 2010). If a company focuses badly or too intently on its CSR claims, consumers may believe that it is trying to hide something (Brown and Dacin, 1997). Perceptions of greenwashing or deliberately misleading strategies can damage consumers' attitude toward a company that communicates about its CSR engagements (Peattie et al., 2009), which suggests that the potential benefits of CSR communication for corporate brand evaluation are questionable. Research needs to determine when and why CSR communication positively enhances corporate brand evaluations and when and why it damages them. Several studies suggest that part of the answer may stem from a greater understanding of how consumers decode the motivations behind CSR communication (Dean, 2004; Pirsch et al., 2007; Van de Ven, 2008).

\section{Controllable CSR communication versus uncontrollable CSR information}

Two types of CSR information sources differ from a consumer perspective: companycontrolled communication (part of the corporate identity mix, Van Riel, 1995) and uncontrolled information, such as word of mouth, mass media, or non-governmental 
organisations' (NGO) communications (Balmer and Gray, 1999; Balmer et al., 2007; Bernstein, 2009; Du et al., 2010). With regard to ethical corporate identity, "uncontrolled communication is in need of increased attention" (Balmer et al., 2007, p.9), because consumers have access to independent sources of information and can compare information provided by the company with evaluations from third parties, such as sustainability ratings. Uncontrolled sources of information have increased in response to consumers' demand for more credible information about environmental concerns. For example, $71 \%$ of French consumers report difficulties evaluating the real impact of environmental innovations (IFOP, 2008). Various third parties, including NGOs, consulting agencies, and media, publish independent general information or sustainability evaluations of companies' CSR practices (e.g., the guide Shopping for a better world, the Web site www.climatecounts.org, the magazine Fortune).

Swaen and Vanhamme (2005) note that the use of a source that is not perceived as controlled by the company increases the positive impact of CSR campaigns. Information from third parties, such as reviews (Chen and Xie, 2005), ratings (Larceneux, 2007), or visible labels of quality (Dickson, 2001), may be influential if they are easily accessible, comprehensible, persuasive, and minimise cognitive requirements for consumers (Carpenter and Larceneux, 2008). Therefore, the interaction between third parties' uncontrolled information and companies' controlled CSR communication may be strategic for determining consumers' attitude toward the corporate brand. We build on attribution theory to derive a clearer understanding of how consumers perceive and respond to CSR communication. Specifically, we investigate the influence of a sustainability rating provided by an uncontrolled information source on consumers' response to the CSR controlled communication issued by a company on its commercial Web site. 


\section{CONCEPTUAL FRAMEWORK AND HYPOTHESES}

\section{Attribution theory, sustainability ratings, and company's perceived motives}

Attribution theory describes the way people make causal inferences to explain their own or others' behaviour (Heider, 1944; Kelley, 1973; Kelley and Michela, 1980). In marketing literature, this theory helps explain consumers' responses to product failures (Folkes, 1984; Dawar and Pillutla, 2000) and their evaluations of companies that engage in social sponsorship (Rifon et al., 2004) or cause-related marketing (Ellen et al., 2000; Dean, 2003; Sjovall and Talk, 2004), two forms of CSR engagements. As in previous literature, Heider's (1944) framework could be used as a means to explain how consumers interpret the company's CSR communication and react to it. Though Du and colleagues (2010) suggest that favourable CSR attributions are a key challenge of CSR communication, previously, the attribution theory has not been tested experimentally in this specific context.

Following Heider (1944), we distinguish two types of causal attributions for CSR communication: attributions to the dispositions of the actor (intrinsic motives) and attributions to environmental factors (extrinsic motives). When faced with CSR communication, consumers may infer a genuine environmental consciousness by the company (intrinsic motive) or an attempt to take opportunistic advantage of sustainable development trends (extrinsic motive).

When consumers observe that a company communicates about its CSR engagement but have no other information about the firm, they probably attribute this communication to the current sustainability trend, which is an extrinsic motive. In this vein, the more socially desirable the perceived behaviour is, the more extrinsic its causal attribution (Kelley, 1973).

External information may help the consumer elaborate more informed attributions (Kelley, 1973). Sustainability ratings from independent agencies provide this kind of information by summarising stakeholders' evaluations of companies' efforts to take social and 
environmental principles into account in their activities (Gotsi and Wilson, 2001). To predict how consumers may use these ratings to make causal attributions about an advertised engagement, we use Kelley's (1973) co-variation model. Three elements constitute this model. Consensus refers to the degree to which others adopt the same behaviour, distinctiveness to the degree to which this behaviour occurs only within a particular situation or is repeated by the actor in other situations, and consistency to the degree to which the behaviour is repeated across time (Sjovall and Talk, 2004).

Based on these three elements, the consumer may attribute the company's advertised engagement to extrinsic motives when most of its competitors engage in the same behaviour at the same time (social consensus), when the company engages in only one CSR activity instead of various ones (distinctiveness), or when CSR engagements are not frequent company practices (no consistency). When a company's global sustainability rating, provided by an independent and credible third party, is very positive, it means that the company respects sustainability principles in various ways (i.e., its engagements are non-distinctive) and on a frequent basis (i.e., its engagements are consistent). As a result, consumers should attribute the advertised engagement to the company's genuine social consciousness (i.e., intrinsic motives). In contrast, a poor sustainability rating should drive CSR engagement attributions to more extrinsic motives (Regan et al., 1974; Sherry, 1983; Sjovall and Talk, 2004), such as an attempt to take advantage of current trends.

In turn, we suppose that CSR engagement perceived motives should transfer to CSR communication perceived motives according to Feldman and Lynch's (1988) accessibilitydiagnosticity model. In this model, the likelihood that any chunk of information will be used as an input for judgment depends on the accessibility of this input compared with that of alternative inputs (i.e., perceived vividness) and its diagnosticity (i.e., perceived relevance) (Feldman and Lynch, 1988; Herr et al., 1991). In this research, we consider the attribution 
about the engagement as the basis on which the attribution regarding the communication forms. As context-based cues, sustainability ratings activate and make salient the attribution regarding the engagement (Menon et al., 1995), increasing its accessibility. Furthermore, sustainability ratings, which are unambiguous by nature (i.e., without multiple interpretations), should increase the consumer's confidence in the attribution regarding the engagement, which in turn increases the diagnosticity of the latter to form the attribution about the communication (Lord et al. 1979). If consumers have no other information to explain the company's motives to communicate (i.e., are not familiar with the corporate brand and its sustainability activities, as is common), no alternative inputs are accessible, so the transfer from the attribution of the corporate brand's engagement to the attribution of the communication should occur automatically. Therefore, we hypothesise:

H1: Consumers perceive a company's motives to communicate as (a) more intrinsic and (b) less extrinsic when the company earns a good rather than a poor sustainability rating.

To gain a deeper understanding of the formation of intrinsic motives, attribution theory also suggests the mediating role of perceived effort.

On the one hand, sustainability ratings may influence the way consumers evaluate the company's general CSR effort after their exposure to the communication. Two identical efforts might be perceived differently by consumers, depending on situational factors (Tversky and Kahneman, 1974). In marketing research, many academics support such framing effects and show that when people doubt an offer's credibility, they tend to discount its value compared with offers of an equal amount (Gupta and Cooper, 1992). In the context of CSR communication, a poor sustainability rating may prompt consumers' scepticism toward the advertised message (Du et al., 2010), leading them to discount the company's CSR 
effort compared with an equivalent CSR engagement communicated without any other information.

On the other hand, attribution theory posits that the amount of effort expended by an actor indicates its intrinsic motives, because such efforts require willingness (Weiner, 1979). In our study context, a company's perceived effort should reflect the degree of its commitment to the cause, inhibit consumers' scepticism toward the message (Pomering and Johnson, 2009; Du et al., 2010) and reveal a genuine social consciousness (Ellen et al., 2000). Everything else being equal, the company's motive to engage in good practices should be perceived as more intrinsic when its efforts appear strong rather than weak. In turn, the accessibility-diagnosticity model suggests that the consumer should transfer perceived motives from the advertised engagement to the CSR communication itself. In this sense, we expect that the level of CSR effort, as perceived by consumers on the basis of the company's CSR communication, partially mediates the effect of sustainability ratings on consumers' perceptions of an intrinsic motive. Therefore, we postulate:

H2: A company's perceived CSR effort partially mediates the impact of the sustainability rating on its perceived intrinsic motives to communicate.

\section{Perceived motives and corporate brand evaluation}

Previous studies investigate the consequences of attributions (Kelley and Michela, 1980) and suggest that an attribution of a specific behaviour as intrinsically or extrinsically motivated influences attitudes toward the actor (Robertson and Rossiter, 1974; Folkes, 1984; Klein and Dawar, 2004).

In the context of moral behaviour, the perception of an actor's intrinsic motive reflects the degree to which a person genuinely experiences feelings and suggests recognition of a certain amount of transparency, which increases perceived sincerity (Weiner and Peter, 1973). In contrast, a behaviour attributed to extrinsic motives is perceived as dishonest and 
misleading for the consumer. It suggests that the action would not have been initiated without a reward and therefore appears opportunistic (Condry, 1977; Lepper and Greene, 1978). In the context of CSR communication, an internal attribution should induce more perceived sincerity, because the communication appears to represent an objective unto itself (Ellen et al., 2000). An external attribution instead should induce a perception of self-serving motives (Bendapudi et al., 1996) and therefore weak sincerity.

Finally, previous works reveal the influence of perceived sincerity on message efficiency in the general case of advertising (MacKenzie and Lutz, 1989; Goldsmith et al., 2000) and the specific context of sponsorship (Barone et al., 2000; Speed and Thompson, 2000). These studies focus on the effects of perceived sincerity at the product brand level. For CSR communication, we consider the corporate brand level and adopt the corporate branding paradigm proposed by Balmer and colleagues (Balmer, 1998; Balmer and Greyser, 2007; Mukherjee and Balmer, 2007). We postulate the influence of perceived motives on corporate brand evaluation as follows:

H3: (a) Perceived intrinsic motives increase corporate brand evaluation, whereas (b) perceived extrinsic motives decrease it.

Figure 1 represents the three hypotheses of our conceptual framework.

\section{Insert Figure 1}

\section{Sustainability ratings and corporate brand evaluation}

To proceed beyond investigating the attribution route that underlies CSR communication mechanisms, we also examine the effect of sustainability ratings on corporate brand building by CSR communication.

Previous research (Creyer and Ross, 1997; Mohr and Webb, 2005) notes the asymmetric effects of societal information on consumers' evaluations, such that negative information (e.g., crises) causes more damage than does positive information provide benefits. 
As we mentioned previously, sustainability ratings can induce framing effects and have a priming effect (Herr, 1989) on subsequent judgments of CSR communication and therefore on corporate brand evaluation. The situation we investigate probably induces an assimilationcontrast effect (Sherif and Hovland, 1961), such that judgments of stimuli depend on the context or internal frame within which they are evaluated, not just the intrinsic stimuli characteristics. Thus, an assessment of a stimulus depends on the perceived discrepancy between the stimulus and the frame. If the discrepancy is weak, an assimilation effect occurs, and the judgment's distortion will be weak. If the discrepancy is stronger, a contrast effect will cause the final judgment to be more polarised than in the assimilation case or in a control group without priming.

In application to our study scenario, consumers exposed to a good sustainability rating before their exposure to CSR communication should experience assimilation, so their judgment differences, compared with a group unexposed to external information, should be tenuous. However, consumers exposed to a poor rating before they review the CSR communication should experience a contrast effect that degrades their evaluations even further. Therefore, we postulate:

H4: In case of CSR communication, there is an asymmetric effect of sustainability ratings on corporate brand evaluation: A good rating improves it less (vs. no rating) than does a poor rating damage it (vs. no rating).

\section{METHODOLOGY}

\section{Experiment and stimuli}

To test the hypotheses, we include three different conditions in a between-subjects experimental design (no rating vs. a poor vs. a good sustainability rating by an independent consumers' association) in the context of CSR communication provided by the company. 
Brand and sector. In all conditions, we first present D'ECO, a fictitious retailer in the furniture and home improvement industry, by showing the respondents a corporate Web site home page (see Appendix 1). We choose a fictitious corporate brand, as have many previous studies (Brown and Dacin, 1997; Swaen and Vanhamme, 2005), to avoid any effects of prior brand familiarity (we checked the availability of the brand name and verified respondents were unfamiliar with it: $\mathrm{m}=1.43$ on a seven-point scale). Furthermore, for the choice of the product category, we rejected several industries because of their high societal involvement (e.g., sports products, toys), for which ceiling effects might occur, and others that are intrinsically controversial (e.g., alcohol, tobacco), which might boost consumers' suspicion. In contrast, the furniture and home improvement industry is an experience-driven category, which makes corporate brand evaluation more critical (Erdem and Swait, 1998). Furthermore, in this sector, many corporate brands (e.g., IKEA) employ a simple brand architecture, in which their corporate brand is the same as their commercial and outlet brands. This characteristic helps remove ambiguity about corporate brand evaluation inferred by consumers. To increase task involvement, the experiment indicates that the fictitious company is a real retailer considering a launch in France.

CSR communication: Web site. We test the brand's commercial Web site (specifically, brand presentation Web page) for four main reasons. First, a Web site is the most frequent medium used to engage in CSR corporate communication (Van de Ven, 2008; Biloslavo and Trnavcevic, 2009); 80\% of Fortune 500 companies mention their involvement on their Web sites (Bhattacharya and Sen, 2004; Kim and Rader, 2010). Such societal communication generally requires a highly accessible but inexpensive medium to avoid accusations of spending more on communication than on the initiatives themselves (Varadarajan and Menon, 1998; Schlegelmilch and Pollach, 2005). Second, Web sites are a preferred medium to communicate CSR involvement because of the richness of 
argumentation and opportunities for interactivity they provide (Coupland, 2005; Biloslavo and Trnavcevic, 2009). Third, for product categories such as furniture and home improvement, Web sites are widespread; $47 \%$ of French consumers look for information on the Internet before buying furniture in an outlet (Netratings French Panel, 2006). Fourth, brand Web sites can target the best brand clients and influence their attitudes and perceptions of the brand's personality (Müller and Chandon, 2004). We therefore anticipate that online CSR communication influences corporate brand evaluation after a single exposure, because corporate image generally is malleable compared with corporate reputation and can be modified rapidly through adequate communication (Gray and Balmer, 1998).

The brand presentation Web page stimulus features four elements: timeline, facts \& figures, our vision, and our engagements. In the generic corporate communication condition, general press information replaces the fourth block, "our engagements" (see Appendix 1).

To ensure realism, we use IKEA's engagements (i.e., producing furniture with wood from certified forests) as inspiration for the environmental claims. We focus on the environmental CSR domain because it represents a universal aspect with high international convergence (i.e., several norms already exist, such as the European Ecolabel, ISO14001, or FSC label to support forest preservation). Furthermore, among societal claims, environmental ones dominate as ecology has achieved tremendous media coverage and is now the most typical domain of CSR (Peattie et al., 2009).

CSR information: Sustainability ratings. The manipulated factor appears in an article extracted from a daily newspaper, Le Monde (equivalent to The New York Times in the United States or The Times in the United Kingdom). The article describes a successful Canadian non-profit organisation that evaluates firms according to various criteria with regard to their sustainable endeavours (see Appendix 1). At the end of the article, it provides the ratings of four companies. In the positive condition (good sustainability rating), D'ECO has 
always obtained a rating above 8 on a ten-point scale, which puts it among the most virtuous companies in its sector. In the negative condition (poor sustainability rating), D'ECO has always obtained a rating below 2 and falls among the worst companies in its sector. These extreme ratings allow the manipulated information to be diagnostic (Herr et al., 1991). We control for the information's credibility in each condition. In the control condition, the article does not appear at all.

\section{Procedure}

The data collection relied on a Web survey, and the experiment consisted of three stages. First, the home page introduced the D'ECO Company and the product categories it sells. Second, the newspaper article containing the ratings appeared. Third, respondents read the Web page stimulus. For each of the three pages (see Appendix 1), a zoom tool enables the respondents to read the material easily, and a "next page" button appears. Then, they completed the questionnaire with no possibility of going back to review the Web pages. Only respondents who noticed that D'ECO supported a cause remain in the final data sample.

To access a generalisable sample, we recruited 122 respondents from the online panel of a professional market research institute. Respondents are between 25 and 45 years of age $($ mean $=34)$. The sample represents various areas in France and is heterogeneous in terms of gender and socio-economic status. We randomly assigned the subjects to the three treatments.

\section{Measures and pre-tests}

All constructs use seven-point scales. To assess consumers' social consciousness and perceptions of the company's motives and CSR effort, we develop ad-hoc scales. For the other measures, we rely on previously validated scales. Similar to previous research, we assess corporate brand evaluation with a global measure of perceived corporate brand equity (adapted from Yoo and Donthu, 2001). We conduct checks for uni-dimensionality and reliability for the multi-items scales and find satisfactory reliability (see Appendix 2). We use 
mean item scores to measure the constructs; in Table 1, we provide the scales' means and standard deviations for each of the experimental treatments.

Insert Table 1

\section{RESULTS}

To determine the respondents' perceptions of the sustainability ratings, we measure D'ECO's perceived reputation in the case of the poor and good sustainability ratings. The manipulation check confirms that the corporate brand's societal reputation is significantly higher in the good sustainability ratings $(\mathrm{m}=5.5)$ than in the poor sustainability ratings $(\mathrm{m}=3.5, \mathrm{t}(175)=$ 9.2, $p<.000)$ condition. Furthermore, the perceived credibility of the newspaper that mentions its sustainability rating is 5.8 on a seven-point scale and does not significantly differ across treatments. Additional analyses show that the three samples are homogenous in terms of their environmental consciousness $\left(\chi^{2}(2)=3.0, \mathrm{~ns}\right)$.

To test H1, we conducted tests of the equality of means, which reveal that sustainability rankings have a significant influence on intrinsic motives but not extrinsic motives. Specifically, respondents perceive the retailer's communication motives as more internal ( $\mathrm{m}=5.6$ vs. $4.2, p<.000)$ and less external (means of 5.7 vs. 5.7 , ns) when the retailer earns a good rather than a poor sustainability rating. Therefore, we find support for H1a but not for H1b.

To test the mediating effect of the retailer's perceived CSR effort on the relationship between the sustainability rating and the retailer's intrinsic motives to communicate, we use three successive regression models, as suggested by Chumpitaz-Caceres and Vanhamme (2003), and we present the results in Table 2.

Insert Table 2 
Model A shows that the company's sustainability rating significantly influences the perceived CSR effort, as it appears in the CSR communication. Model B demonstrates that perceived CSR effort has a significant effect on the retailer's intrinsic motives, even when we control for the sustainability rating (Model C). Thus, the retailer's perceived CSR effort has a partial mediating effect on the impact of sustainability ratings on the retailer's perceived intrinsic motives, in support of $\mathrm{H} 2$.

To test H3, we apply a new linear regression model (Model D) that considers the effect of the company's intrinsic and extrinsic motives to communicate on corporate brand evaluation. This model is significant, and as we expected and in support of $\mathrm{H} 3 \mathrm{a}$, the results exhibit the significant and positive effect of consumers' perceptions of intrinsic motives on corporate brand evaluation. However, corporate brand evaluation is not influenced by the company's perceived extrinsic motives, so we must reject $\mathrm{H} 3 \mathrm{~b}$.

To further investigate $\mathrm{H} 1, \mathrm{H} 2$ and $\mathrm{H} 3$ and check for potential problems of collinearity within constructs measures, we use structural equation modelling. Thus we test the path from sustainability ratings to corporate brand evaluation, going through company's perceived effort and motives (intrinsic and extrinsic). The analysis is indicative as the number of observations is weak (122) for the model complexity (30 parameters), leading to underestimated indicators. The indicators of model fit are satisfactory, apart from a weak GFI $\left(\chi^{2}(48)=99.4, p=.000\right.$, $\chi^{2} / \mathrm{df}=2.1$, goodness-of-fit index $=.880$, confirmatory fit index $=.948$, normed fit index $=.906$, root mean squared error of approximation $=.094$, square root mean residual $=.075$ ) . The four constructs-perceived effort, perceived intrinsic motives, perceived extrinsic motives, and corporate brand evaluation-achieve good levels of reliability (Jöreskog's $\rho$ $=.887, .873, .800$, and .944 , respectively) and convergent validity (average variance extracted $=.797, .697, .572$, and .850 , respectively). The path coefficients are significant; between the rating and company's perceived effort, the standardised coefficient is $.52(p<.000)$; between 
the company's perceived effort and intrinsic motives, the standardised coefficient is .810 ( $p$ $<.000)$, and between intrinsic motives and corporate brand evaluation, it is .670 $(p<.000)$. However they are not significant between perceived effort and extrinsic motives (.030, ns) or between extrinsic motives and corporate brand evaluation $(-.046$, ns), meaning that brand evaluation is not influenced by perceived effort (and then extrinsic motives). Thus, structural equation modelling tends to confirm the preceding results pertaining to $\mathrm{H} 1, \mathrm{H} 2$ and $\mathrm{H} 3$.

Finally, we test our last hypothesis with a one-way ANOVA, which we use to consider the influence of sustainability ratings on corporate brand evaluation when the company uses CSR communications. The ratings have an impact on corporate brand evaluation $(\mathrm{F}(2,121)=$ 20.0, $p<.000)$, such that it increases in response to a good sustainability rating $(\mathrm{m}=5.5)$ compared with the control case of no rating $(\mathrm{m}=5.0, \mathrm{t}(85)=2.1, p=.035)$. Similarly, the corporate brand evaluation is lower when the sustainability rating is poor $(\mathrm{m}=3.8)$ compared with the control case $(\mathrm{m}=5.0, \mathrm{t}(78)=4.0, p<.000)$. Sustainability rating knowledge thus appears to leverage the corporate brand evaluation when the rating is good, but it reduces it even more when the rating is poor, in support of H4. Figure 2 depicts this asymmetric effect of sustainability ratings on corporate brand evaluations.

Insert Figure 2

\section{DISCUSSION}

\section{Theoretical, managerial, and societal implications}

Building on previous works (Balmer and Greyser, 2003, 2007; Balmer et al., 2007; Fukukawa et al., 2007), this research contributes to a greater understanding of the manner in which consumers, those often forgotten stakeholders, respond to CSR policies in the context of an accessible, consumer goods, corporate brand. We offer several interesting findings regarding how consumers perceive companies' societal communication; in general, we demonstrate the 
influence of sustainability ratings on perceptions of a company's CSR efforts, which influence their perceptions of the company's motives. As the central variable for evaluations of corporate communications, intrinsic motives have positive effects on corporate brand evaluation. Klein and Dawar (2004) have offered evidence of the central role of perceived motives in their research about client complaints, and Sjovall and Talk (2004) similarly postulate its effect in the specific case of CSR communication, though no work has tested it empirically before now.

This empirical confirmation of the relevance of the attribution process for explaining consumers' CSR communication evaluations represents an important result: "Real" consumers examine communication messages and wonder about the company's motives. In a sense, this study replicates previous research pertaining to other communication domains that appear similar to CSR communication, such as sponsorship (Rifon et al., 2004) and causerelated marketing (Dean, 2004). As Rifon and colleagues (2004) provide in their analysis of the impact of sponsor and brand congruence on consumers' responses, we validate the mediating role of a company's intrinsic motives on the effect of CSR communication on corporate brand evaluation.

We also confirm the distinction between extrinsic versus intrinsic company motives. Motives do not represent opposite sides of the same construct, which actually ranges from altruistic (intrinsic) to opportunistic (extrinsic) motives, but rather form two different dimensions (Pearson $\rho=-.046$, ns). We thus shed additional light on the different roles these two dimensions play for CSR communication's persuasiveness, in that the only dimension that affects corporate brand evaluation is perceived intrinsic motives. To enhance their corporate brand evaluations, consumers must perceive intrinsic motives for CSR communication. Yet consumers clearly (mean 5.7 out of 7) and homogeneously (std. dev. = 1.0 versus 1.3 for internal motivations) perceive extrinsic motives by companies, though these 
motives appear well-accepted by French consumers, who understand the economic motives that often underlie sustainable development efforts. They do not necessarily reduce corporate brand evaluation — a positive finding from a managerial point of view.

Beyond generalising the application of attribution theory to a new domain, we investigate a new antecedent of the attribution process, namely, sustainability ratings. The experiment reveals their dual effects on intrinsic motives. Specifically, ratings have a direct effect on perceptions of intrinsic motives, because they act as a signal of the nondistinctiveness and consistency of the engagement communicated with the company's other behaviours. Moreover, this effect is partially mediated by the company's perceived CSR effort, which indicates a framing effect of sustainability ratings that may bias perceptions of the company's CSR efforts. Perceived CSR effort also seems to offer a key variable for explaining CSR communication efficiency; despite its appearance in a few investigations (Ellen et al., 2000), it clearly deserves more attention to delineate all the factors that influence its evaluation. Sustainability ratings influence intrinsic motives, which is an interesting result in the context of company communications. Companies that display intrinsic motivations earn greater rewards for their efforts, in that their communication more efficiently enhances their corporate brand evaluation. Highlighting their CSR efforts using objective arguments therefore provides a good method for them.

In addition to the findings regarding the attribution process, we offer a fruitful examination of the direct effects of the combination of sustainability ratings and CSR communication on corporate brand evaluation. This study confirms Balmer and colleagues' (2007) intuition that external sources (i.e., uncontrolled information) play important roles in ethical corporate communication. By validating the asymmetric impact of good and poor ratings, we demonstrate that in the case of CSR communication, a good rating has limited impact on corporate brand evaluations relative to the absence of information, whereas a poor 
rating really damages corporate brand evaluation. On the one hand, we might lament that virtuous companies do not benefit more from their past behaviours compared with "neutral" firms, likely because consumers establish a general climate of confidence in companies, as long as they have not been tainted by scandals or crisis. However, it might be interesting to examine this finding among a population of highly sceptical consumers, because the initial finding reveals only an average opinion. Moreover, we might theorise that consumers' confidence decreases as more denunciations identify abuses and as they learn more about ecological issues. On the other hand, corporate brand evaluation declines with poor ratings, which appear to inform perceptions of CSR communication. Therefore, in response to the profusion of CSR claims, independent information about companies' sustainability performance helps consumers explicate CSR communication more accurately.

From a broader societal perspective, sustainability ratings play a significant role in helping consumers make more responsible evaluations, which may have great value, especially when consumers appear weakly sceptical. Such sources of information can penalise non-virtuous companies through classical market mechanisms, sensitise consumers further, and encourage virtuous firms to persevere in their CSR practices. Sustainability ratings thus can resolve the prisoner's dilemma evoked in the introduction. Yet a question still arises: Should governments ensure the availability and seriousness of such sources? The task would not be easy, considering the complexity of analysing the global environment impact of every company's activities, but a potential approach could compel firms to publish a certified report, similar to requirements in the accounting domain.

\section{Limitations and directions for further research}

Despite its contributions, this research is not without limitations. First, we rely on fictitious, and therefore less realistic, stimuli. Although a fictitious company enables us to focus on the effects of societal information rather than any pre-existing knowledge respondents might 
possess about a real company, further research should investigate more realistic stimuli. Second, it would be interesting to replicate our results in other cultural contexts, because CSR consciousness may vary across them (Grbac and Loncaric, 2009). Third, the furniture and home improvement product category generally displays an intermediate level of CSR communication intensity (cf. grocery retailers) and an intermediate level of perceived risk regarding CSR issues (cf. oil companies). We suspect the attribution process may be less significant in sectors in which CSR communication is a prerequisite, because consumers probably treat the information more superficially, but more significant in controversial sectors, which boost consumers' suspicions. Fourth, sustainability ratings affect corporate brand evaluations when consumers have not developed any comprehensive frame to explain the company's CSR communication. When consumers benefit from pre-existing, specific knowledge (e.g., about the company's or sector-specific practices) that explains CSR communication motives, the automatic influence from the advertised engagement to the CSR communication, as we postulated in $\mathrm{H} 1$ and $\mathrm{H} 2$, might be moderated. Fifth, our experiment only manipulates support for an environmental cause (i.e., forest preservation). Extending the research to other causes, other forms of involvement (e.g., waste and energy reduction, product life cycle optimisation), or other media (e.g., traditional advertising, packaging) would be interesting directions for further research.

In addition to these experimental replications, investigating signals other than sustainability ratings and their effects on a company's perceived intrinsic motives could deepen our understanding of attribution processes. If the diffusion of sustainability ratings is not within the company's control, perhaps more controllable signals, such as the nature and amount of involvement, the communication medium, the message, or the means of communicating, offer areas for further study. 
From a general perspective, this study represents part of a growing body of research that considers the societal implications, as well as the managerial implications, of marketing activities, supporting Lazer's (1969, p.3) early intuition that

"Marketing is not an end in itself. It is not the exclusive province of business management. Marketing must serve not only business but also the goals of society. It must act in concert with broad public interest. For marketing does not end with the buy-sell transaction—its responsibilities extend well beyond making profits." 


\section{References}

Alon, I., Lattemann, C., Fetscherin, M., Li, S. and Schneider A-M.: 2010, "Usage of public corporate communications of social responsibility in Brazil, Russia, India and China (BRIC)", International Journal of Emerging Markets, 5(1), 6-22.

ARPP (French Advertising Regulation Bureau): 2009, “Advertising and environment 2008”, study report available at www.arpp-pub.org.

Balmer, J.M.T.: 1998, "Corporate identity and the advent of corporate marketing”, Journal of Marketing Management, 14(8), 963-996.

Balmer, J.M.T.: 2009, “Corporate marketing: apocalypse, advent and epiphany”, Management Decision, 47(4), 544-572.

Balmer, J.M.T., Fukukawa, K. and Gray, E.R.: 2007, “The nature and management of ethical corporate identity: a commentary on corporate identity, corporate social responsibility and ethics", Journal of Business Ethics, 76(1), 7-15.

Balmer, J.M.T. and Gray, E.R.: 1999, “Corporate identity and corporate communications: creating competitive advantage", Corporate Communication: An International Journal, 4(4), 171-176.

Balmer, J.M.T. and Greyser, S.A.: 2003, Revealing the corporation. Perspectives on identity, image, reputation, corporate branding, and corporate level marketing, (Routledge, New York).

Balmer, J.M.T. and Greyser, S.A.: 2007, “Corporate marketing: integrating corporate identity, corporate branding, corporate communications, corporate image and corporate reputation", European Journal of Marketing, 40(7-8), 730-741. 
Barone, M.J., Miyazaki, A.D. and Taylor, K.A.: 2000, "The influence of cause-related marketing on consumer choice: does one good turn deserve another?", Journal of the Academy of Marketing Science, 28(2), 248-262.

Bendapudi, N., Singh, S. and Bendapudi, V.: 1996, "Enhancing helping behavior: an integrative framework for promotion planning", Journal of Marketing, 60(3), 33-49.

Benoit-Moreau, F. and Parguel, B.: 2010, "Building brand equity with environmental communication: an empirical investigation in France", Euromed Journal of Business (forthcoming).

Bernstein, D.: 2009, "Rhetoric and reputation: some thoughts on corporate dissonance", Management Decision, 47(4) 603-615.

Bhattacharya, C.B. and Sen, S.: 2004, "Doing better at doing good: when, why and how consumers respond to corporate social initiatives", California Management Review, 47(1), 924.

Biloslavo, R. and Trnavcevic, A.: 2009, "Web sites as tools of communication of a "green" company", Management Decision, 47(7), 1158-1173.

Bradford, R.: 2007, “Greenwash confronted: misleading advertisement regulation in the European Union and its member states", study report available at www.foeeurope.org/corporates/pdf/greenwash_confronted.pdf.

Brown, T.J. and Dacin, P.A.: 1997, “The company and the product: corporate associations and consumer product responses", Journal of Marketing, 61(1), 68-84.

Carpenter, M. and Larceneux, F.: 2008, "Label equity and the effectiveness of values-based labels: an experiment with two French PGI labels", International Journal of Consumer Studies, 32(5), 499-519. 
Chen, Y. and Xie, J.: 2005, "Third-party product review and firm marketing strategy", Marketing Science, 24(2), 218-240.

Chumpitaz-Caceres, R. and Vanhamme, J.: 2003, "Les processus modérateurs et médiateurs: distinction conceptuelle, aspects analytiques et illustrations", Recherche et Applications en Marketing, 18(2), 67-100.

Clarkson, M.B.E.: 1995, “A stakeholder framework for analyzing and evaluating corporate social performance", Academy of Management Review, 20(1), 92-117.

Condry, J.: 1977, "Enemies of exploration: self-initiated versus other-initiated learning", Journal of Personality and Social Psychology, 35(7), 459-477.

Coupland, C.: 2005, “Corporate social responsibility as argument on the web", Journal of Business Ethics, 62(4), 355-366.

Creyer, E.H. and Ross, W.T.: 1997, “The influence of firm behavior on purchase intention: do consumers really care about business ethics?", Journal of Consumer Marketing, 14(6), 421432.

Dawar, N. and Pillutla, M.: 2000, "Impact of product-harm crisis on brand equity: the moderating role of consumer expectations”, Journal of Marketing Research, 37(2), 215-226.

Dean, D.: 2003, “Consumer perception of corporate donations. Effects of company reputation for social responsibility and type of donation", Journal of Advertising, 32(4), 91-102.

Dickson, M.A.: 2001, “Utility of no sweat labels for apparel consumers: profiling label users and predicting their purchases", Journal of Consumer Affairs, 35(1), 96-115.

Donaldson, T. and Preston, L.E.: 1995, “The stakeholder theory of the corporation: concepts, evidence, and implications", Academy of Management Review, 20(1), 65-91. 
Du, S., Bhattacharya, C.B. and Sen, S.: 2010, Maximizing business returns to Corporate Social Responsibility (CSR): the role of CSR communication, International Journal of Management Reviews, 12(1), 8-19.

Ellen, P.S., Mohr, L.A. and Webb, D.J.: 2000, "Charitable programs and the retailer: do they mix?", Journal of Retailing, 76(3), 393-406.

Erdem, T. and Swait, J.: 1998, "Brand equity as a signaling phenomenon", Journal of Consumer Psychology, 7(2), 131-157.

Feldman, J.M. and Lynch, J.G.Jr.: 1988, "Self-generated validity and other effects of measurement on belief, attitude, intention, and behaviour", Journal of Applied Psychology, 73(3), 421-435.

Folkes, V.S.: 1984, "Consumers reactions to product failure: an attributional approach", Journal of Consumer Research, 10(4), 398-409.

Folkes, V.S. and Kamins, M.A.: 1999, 'Effects of information about firms' ethical and unethical actions on consumers' attitudes", Journal of Consumer Psychology, 8(3), 243-259.

Fukukawa, K., Balmer, J.M.T., and Gray, E.R.: 2007, "Mapping the interface between corporate identity, ethics and corporate responsibility", Journal of Business Ethics, 76(1), 1-5.

Goldsmith, R.E., Lafferty, B.A. and Newell, S.J.: 2000, “The impact of corporate credibility and celebrity credibility on consumer reaction to advertisements and brands", Journal of Advertising, 29(3), 43-54.

Gotsi, M. and Wilson, A.M.: 2001, “Corporate reputation: seeking a definition”, Corporate Communications: An International Journal, 6(1), 24-30.

Gray, E.R. and Balmer, J.M.T: 1998, "Managing corporate image and corporate reputation”, Long Range Planning, 31(5), 695-702. 
Grbac, B. and Loncaric, D.: 2009, "Ethics, social responsibility and business performance in a transition economy", EuroMed Journal of Business, 4(2), 143-158.

Gupta, S. and Cooper, L.G.: 1992, "The discounting of discounts and promotion thresholds", Journal of Consumer Research, 19(3), 401-411.

Heider, F.: 1944, "Social perception and phenomenal causality", Psychological Review, 51(6), 358-374.

Herr, P.M.: 1989, “Priming price: prior knowledge and context effects”, Journal of Consumer Research, 16(2), 67-75.

Herr, P.M., Kardes, F.R. and Kim, J.: 1991, "Effects of word-of-mouth and product-attribute information on persuasion: an accessibility-diagnosticity perspective", Journal of Consumer Research, 17(4), 454-462.

Hoeffler, S. and Keller, K.L.: 2002, "Building brand equity through corporate societal marketing", Journal of Public Policy and Marketing, 21(1), 78-89.

Hutton, J., Goodman, M., Alexander, J. and Genest, C.: 2001, "Reputation management: the new face of corporate public relations?", Public Relations Review, 27(3), 247-261.

IFOP (2008), Green label equity (subscription study).

Kelley, H.H.: 1973, “The processes of causal attribution”, American Psychologist, 28(2), 107128.

Kelley, H.H. and Michela, J.L.: 1980, “Attribution theory and research", Annual Review of Psychology, 31, 457-501.

Klein, J. and Dawar, N.: 2004, "Corporate social responsibility and consumers attributions and brand evaluations in a product-harm crisis", International Journal of Research in Marketing, 21(3), 203-217. 
Kim, S. and Rader, S.: 2010, "What they can do versus how much they care: Assessing corporate communication strategies on Fortune 500 web sites", Journal of Communication Management, 14(1), 59-80.

Kotler, P. and Lee, N.: 2005, Corporate social responsibility. Doing the most good for your company and your cause, (John Wiley and Sons Inc, Hoboken, NJ).

Larceneux, F.: 2007, “Buzz and recommendations on Internet. What impacts on box-office?”, Recherche et Applications en Marketing, 22(3), 45-64.

Lazer, W.: 1969, "Marketing's changing social relationships", Journal of Marketing, 33(1), 39.

Lepper, M.R. and Greene, D.: 1978, The hidden costs of reward, (Erlbaum, Hillsdale, NJ). MacKenzie, S. and Lutz, R.: 1989, “An empirical examination of the structural antecedents of attitude toward the ad in an advertising pretesting context", Journal of Marketing, 53(2), 4865.

Lord, C.G., Ross, L. and Lepper, M.R.: 1979, "Biased assimilation and attitude polarization: the effects of prior theories on subsequently considered evidence", Journal of Personality and Social Psychology, 37(11), 2098-2109.

Maignan, I. and Ferrell, O.C.: 2004, "Corporate social responsibility and marketing: an integrative framework", Journal of the Academy of Marketing Science, 32(1), 3-19.

Menon, G., Raghubir, P. and Schwarz, N.: 1995, "Behavioral frequency judgments: an accessibility-diagnosticity framework", Journal of Consumer Research, 22(2), 212-228.

Mohr, L.A. and Webb, D.J.: 2005, “The effects of corporate social responsibility and price on consumer responses", The Journal of Consumer Affairs, 39(1), 121-147. 
Morsing, M.: 2006, “Corporate social responsibility as strategic auto-communication: on the role of external stakeholders for member identification", Business Ethics: A European Review, 15(2), 171-182.

Mukherjee, A. and Balmer, J.M.T.: 2007, “New frontiers and perspectives in corporate brand management: in search of a theory", International Studies of Management and Organization, 37(4), 3-19.

Müller, B. and Chandon, J-L.: 2004, “The impact of a World Wide Web site visit on brand image in the motor vehicle and mobile telephone industries", Journal of Marketing Communications, 10(2), 153-165.

Murray, K.B. and Vogel, C.M.: 1997, "Using a hierarchy-of-effects approach to gauge the effectiveness of corporate social responsibility to generate goodwill toward the firm: financial versus nonfinancial impacts", Journal of Business Research, 38(2), 141-159.

Nielsen, A.E. and Thomsen C.: 2009, "CSR communication in small and medium-sized enterprises: a study of the attitudes and beliefs of middle managers", Corporate Communications: An International Journal, 14(2), 176-189.

Peattie, K., Peattie, S. and Ponting, C.: 2009, "Climate change: a social and commercial marketing communications challenge”, EuroMed Journal of Business, 4(3), 270-286.

Pirsch, J., Gupta, S. and Grau, S.L.: 2007, “A framework for understanding corporate social responsibility programs as a continuum: an exploratory study", Journal of Business Ethics, 70(2), 125-140.

Pomering, A. and Johnson, L.W.: 2009, Advertising corporate social responsibility initiatives to communicate corporate image: Inhibiting scepticism to enhance persuasion", Corporate Communications: An International Journal, 14(4), 420-439. 
Regan, D.T., Strauss, E. and Fazio, R.: 1974, “Liking and the attribution process", Journal of Experimental Social Psychology, 10(4), 385-397.

Rifon, N., Choi, S., Trimble, C. and Li, H.: 2004, "Congruence effects in sponsorship. The moderating role of sponsor credibility and consumer attributions of sponsor motive", Journal of Advertising, 33(1), 29-42.

Robertson, T.S. and Rossiter, J.R.: 1974, "Children and commercial persuasion: an attribution theory analysis", Journal of Consumer Research, 1(1), 508-512.

Schlegelmilch, B.B. and Pollach, I.: 2005, "The perils and opportunities of communicating corporate ethics", Journal of Marketing Management, 21(3-4), 267-290.

Sherif, M. and Hovland, C.: 1961, Social judgment: assimilation and contrast effects in communication and attitude change, (Yale University Press, New Haven, CT).

Sherry, J.F.: 1983, "Gift giving in anthropological perspective", Journal of Consumer Research, 10(2), 157-168.

Sjovall, A.M. and Talk A.C.: 2004, "From actions to impressions: cognitive attribution theory and the formation of corporate reputation", Corporate Reputation Review, 7(3), 269-281.

Speed, R. and Thompson, P.: 2000, "Determinants of sports sponsorship response", Journal of the Academy of Marketing Science, 28(2), 226-238.

Swaen, V. and Vanhamme, J.: 2004, "See how 'good' we are: the dangers of using corporate social activities in communication campaigns", Advances in Consumer Research, 31(1), 302303.

Swaen, V. and Vanhamme, J.: 2005, "The use of corporate social responsibility arguments in communication campaigns: does source credibility matter?", Advances in Consumer Research, 32(1), 590-591. 
Tversky, A. and Kahneman, D.: 1974, “Judgment under uncertainty: heuristics and biases”, Science, 185(4157), 1124-1131.

Van de Ven, B.: 2008, "An ethical framework for the marketing of corporate social responsibility", Journal of Business Ethics, 82(2), 339-352.

Van Riel, C.B.M.: 1995, Principles of corporate communication, (Prentice Hall, Hertfordshire).

Vanhamme, J. and Grobben, B.: 2009, “Too good to be true! The effectiveness of CSR history in countering negative publicity”, Journal of Business Ethics, 85(2), 273-283.

Varadarajan, P.R. and Menon, A.: 1988, "Cause-related marketing: a co-alignment of marketing strategy and corporate philanthropy”, Journal of Marketing, 52(3), 58-74.

Wæraas, A. and Ihlen, Ø.: 2009, “Green legitimation: the construction of an environmental ethos", International Journal of Organizational Analysis, 17(2), 84-102.

Weiner, B.: 1979, "A theory of motive for some classroom experiences", Journal of Educational Psychology, 71(1), 3-25.

Weiner, B. and Peter, N.: 1973, “A cognitive-developmental analysis of achievement and moral judgments", Developmental Psychology, 9(3), 290-309.

Yoo, B. and Donthu, N.: 2001, "Developing and validating a multidimensional consumerbased brand equity scale”, Journal of Business Research, 52(1), 1-14. 
Table 1: Descriptive statistics per treatment

\begin{tabular}{cccccc}
\cline { 3 - 5 } & & $\begin{array}{c}\text { CSR perceived } \\
\text { effort }\end{array}$ & Intrinsic motives & $\begin{array}{c}\text { Extrinsic } \\
\text { motives }\end{array}$ & $\begin{array}{c}\text { Corporate brand } \\
\text { evaluation }\end{array}$ \\
\hline Good rating & Mean & 5.7 & 5.6 & 5.7 & 5.5 \\
$(\mathrm{~N}=42)$ & Std dev. & 1.0 & 0.8 & 1.0 & 1.0 \\
\hline No rating & Mean & 5.7 & 5.4 & 5.6 & 5.0 \\
$(\mathrm{~N}=45)$ & Std dev. & 1.2 & 1.2 & 1.1 & 1.4 \\
\hline Poor rating & Mean & 4.6 & 4.2 & 5.7 & 3.8 \\
$(\mathrm{~N}=35)$ & Std dev. & 1.3 & 1.4 & 0.9 & 1.1 \\
\hline
\end{tabular}

Table 2: Regression results

\begin{tabular}{|c|c|c|c|c|c|}
\hline Model & Dependent Variable (Y) & Independent Variables $\left(\mathbf{X}_{\mathrm{i}}\right)$ & Adj $\mathbf{R}^{2}$ & Sd $\beta$ & $\mathrm{T}$ \\
\hline \multirow{3}{*}{ A } & Perceived effort & & 0.095 & & \\
\hline & & (intercept) & & & 14.7 \\
\hline & & Rating & & $0.321 * * *$ & 3.7 \\
\hline \multirow{3}{*}{ B } & Intrinsic motives & & 0.506 & & \\
\hline & & (intercept) & & & 3.4 \\
\hline & & Perceived effort & & $0.714 * * *$ & 11.2 \\
\hline \multirow{4}{*}{$\mathrm{C}$} & Intrinsic motives & & 0.533 & & \\
\hline & & (intercept) & & & 2.6 \\
\hline & & Rating & & $0.185 * *$ & 2.8 \\
\hline & & Perceived effort & & $0.654 * * *$ & 9.9 \\
\hline \multirow{4}{*}{$\mathrm{D}$} & Corporate brand evaluation & & 0.313 & & \\
\hline & & (intercept) & & & 3.1 \\
\hline & & Intrinsic motives & & $0.565 * * *$ & 7.5 \\
\hline & & Extrinsic motives & & -0.053 & -0.7 \\
\hline
\end{tabular}

$* * * p<.001, * * p<.01, * p<.05$. 
Figure 1: Conceptual framework

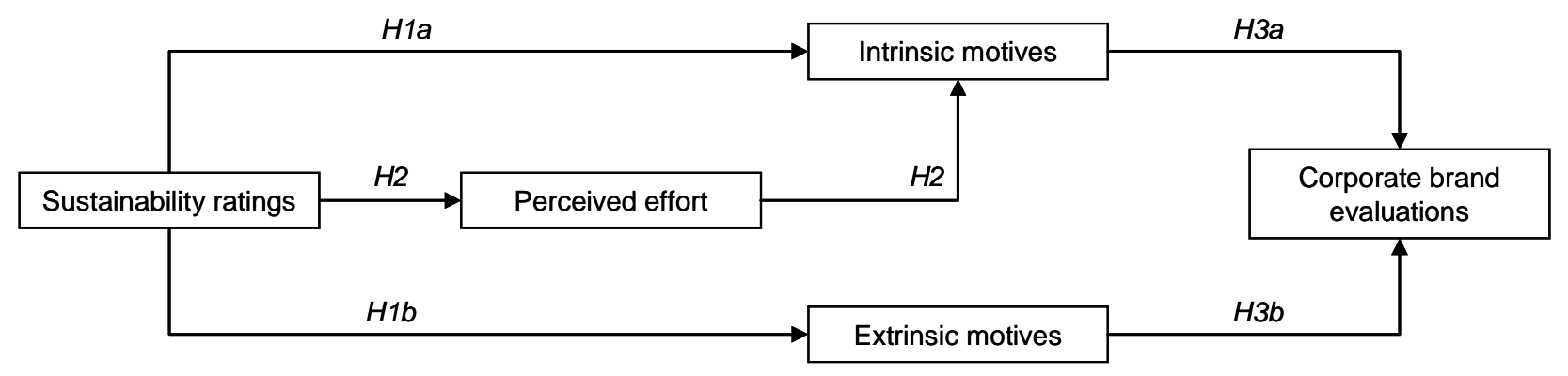

Figure 2: Asymmetric effect of sustainability ratings on corporate brand evaluation

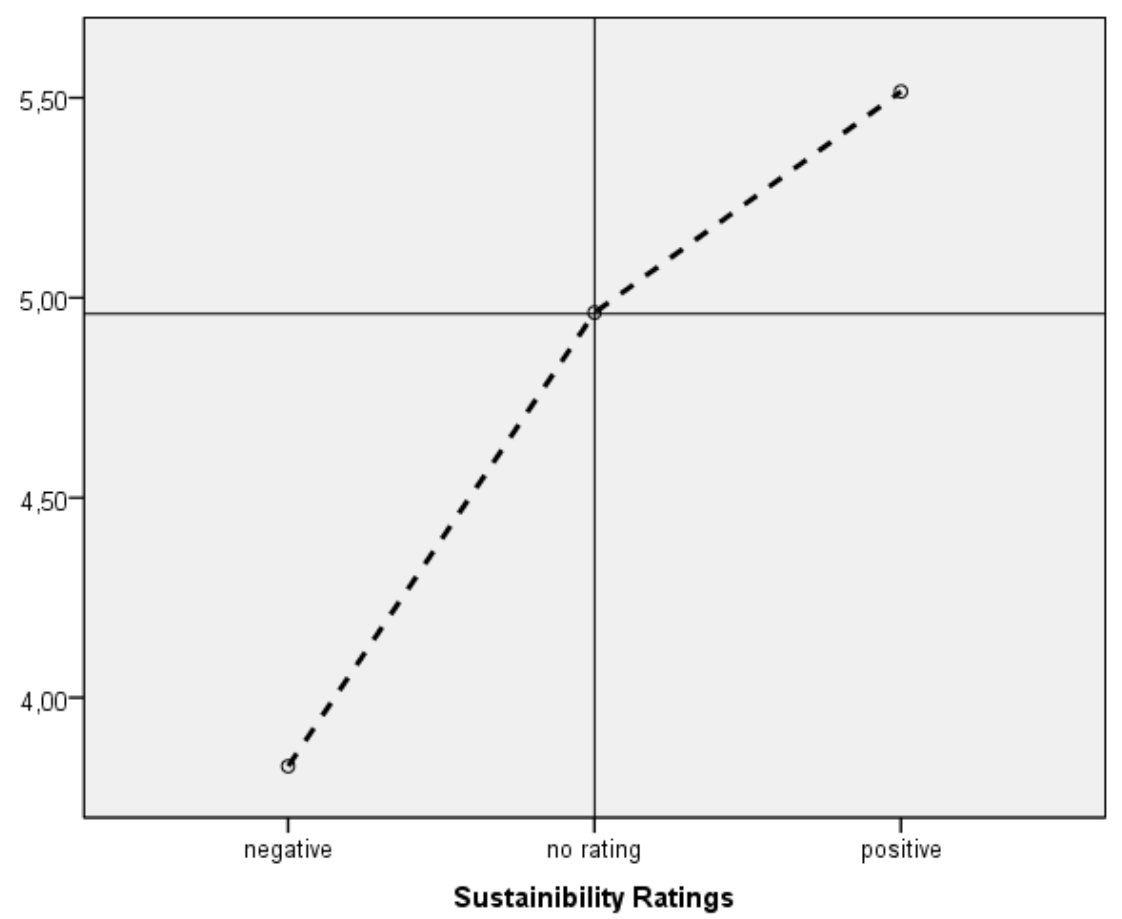




\section{Appendix 1: Experimental stimuli}

D'ECO commercial Web site homepage

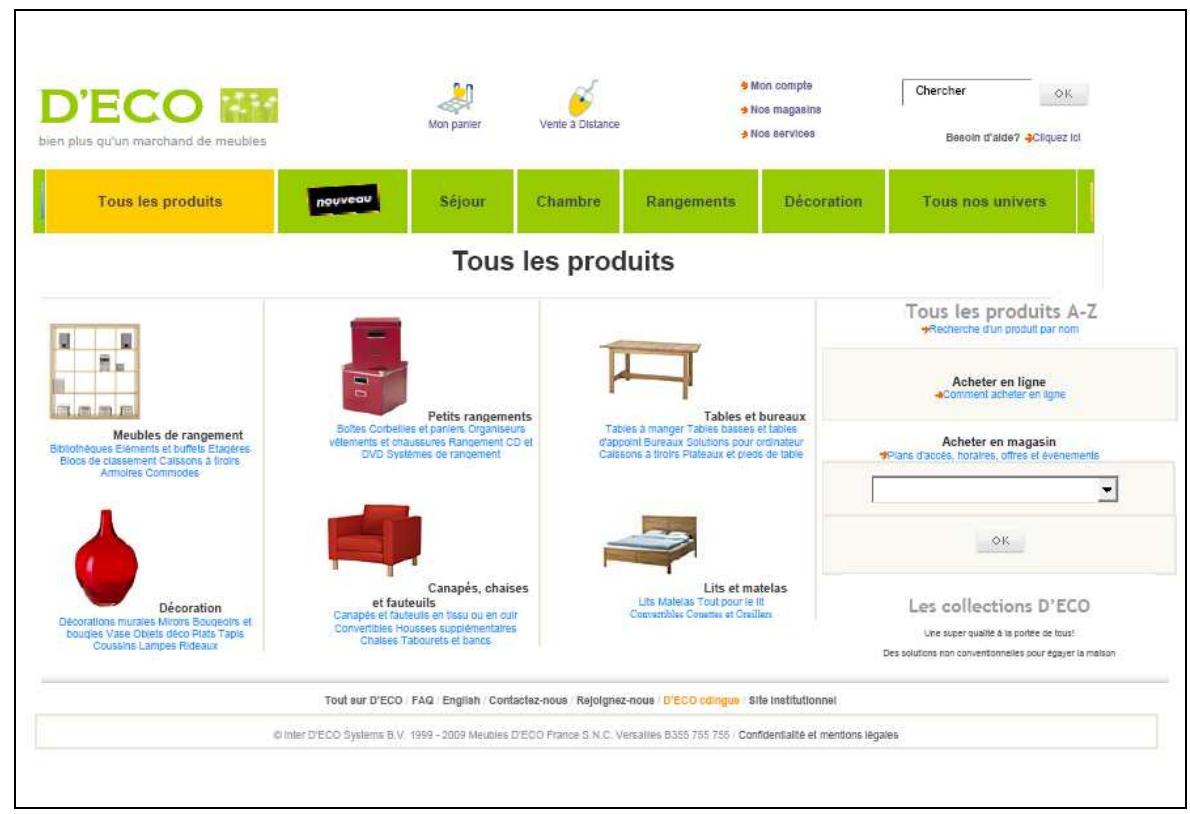

Article mentioning sustainability ratings

“All about D’ECO” Web page
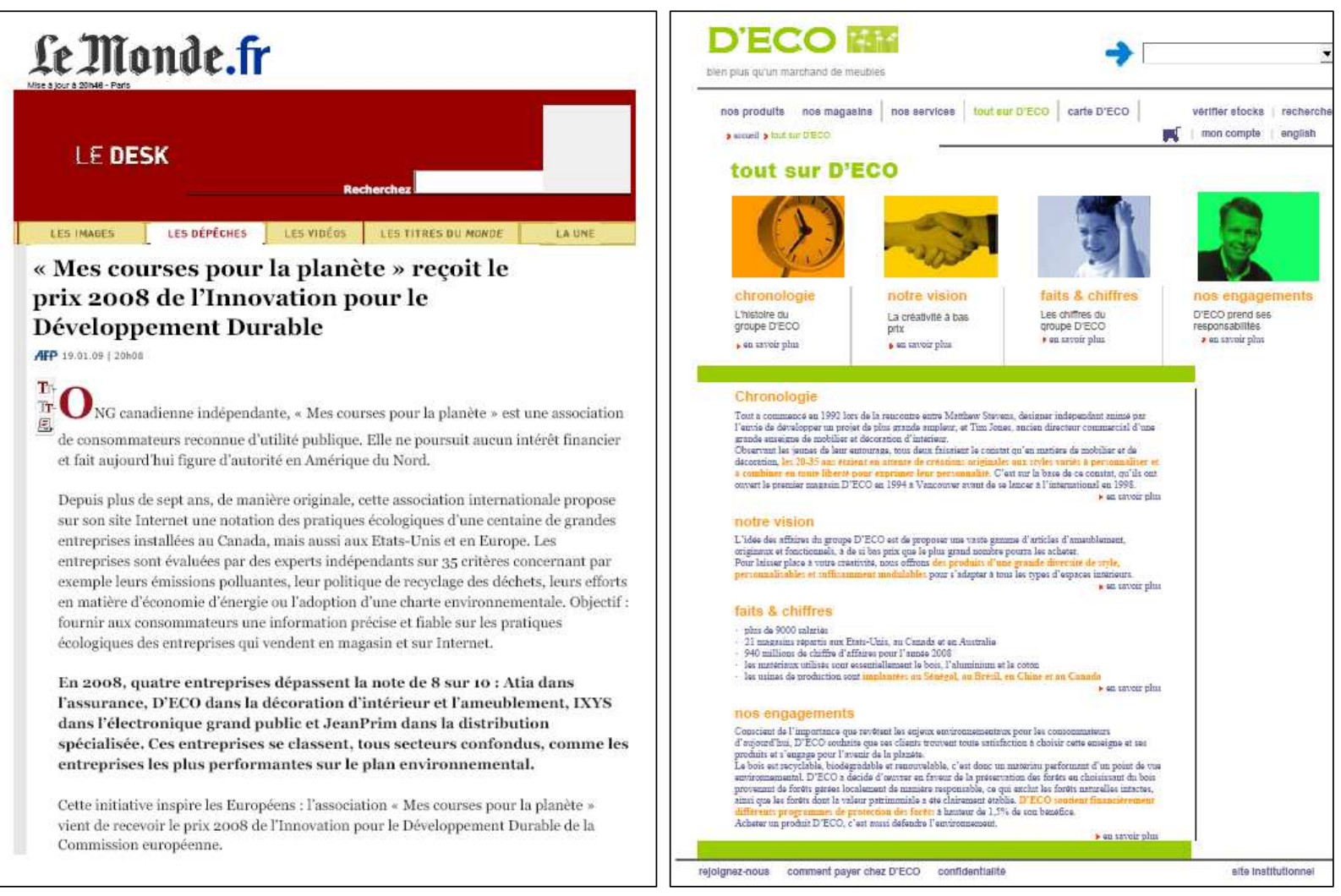


\section{Appendix 2: Scales}

\begin{tabular}{|c|c|c|}
\hline Variable & Instrument & $\begin{array}{c}\text { Reliability } \\
(\text { Cronbach's } \alpha) \\
\end{array}$ \\
\hline $\begin{array}{l}\text { Consumers' } \\
\text { environmental } \\
\text { consciousness } \\
(\text { ad hoc } \text { scale })\end{array}$ & $\begin{array}{l}\text { - I try not to buy from companies that strongly pollute } \\
\text { - When possible, I systematically choose the product that } \\
\text { has the lowest negative impact on the environment } \\
\text { - When I have the choice between two equivalent } \\
\text { products, I always wonder which one pollutes less } \\
\text { before buying }\end{array}$ & 0.92 \\
\hline $\begin{array}{l}\text { Retailer's perceived } \\
\text { intrinsic motives } \\
\quad(\text { ad hoc } \text { scale })\end{array}$ & $\begin{array}{l}\text { In your opinion, why does D'ECO communicate about its } \\
\text { ecological engagement? } \\
\text { - Primarily because D'ECO is really conscious of the } \\
\text { - } \quad \text { Primportance of ecological issues } \\
\quad \text { regarding ecological problems } \\
\text { Primarily to make consumers aware of ecological } \\
\text { issues }\end{array}$ & 0.89 \\
\hline $\begin{array}{l}\text { Retailer's perceived } \\
\text { extrinsic motives } \\
\quad(\text { ad hoc } \text { scale })\end{array}$ & $\begin{array}{l}\text { In your opinion, why does D'ECO communicate about its } \\
\text { ecological engagement? } \\
\text { - Primarily because D'ECO wants to improve its image } \\
\text { - } \quad \text { among consumers } \\
\text { - Primarily because it is fashionable to do so nowadays } \\
\text { Primarily to be likeable to consumers }\end{array}$ & 0.81 \\
\hline $\begin{array}{l}\text { Perceived corporate } \\
\text { brand equity } \\
\text { (adapted from Yoo and } \\
\text { Donthu, 2001) }\end{array}$ & $\begin{array}{l}\text { Four items adapted from Yoo and Donthu (2001) } \\
\text { - Even if another brand has the same features as D'ECO, I } \\
\text { would prefer to buy D'ECO } \\
\text { - If there is another brand which products are as good as } \\
\text { D'ECO, I would prefer to buy D'ECO } \\
\text { - If the products of another brand were not different from } \\
\text { those of D'ECO in any way, it would be smarter to purchase } \\
\text { D'ECO }\end{array}$ & 0.92 \\
\hline $\begin{array}{l}\text { Retailer's perceived } \\
\text { CSR effort } \\
(\text { ad hoc } \text { scale })\end{array}$ & $\begin{array}{l}\text { - D'ECO's effort for the environment is important } \\
\text { - D'ECO dedicates a great amount of resources to its } \\
\text { ecological commitment }\end{array}$ & 0.88 \\
\hline $\begin{array}{c}\text { CSR reputation } \\
\text { (manipulation check) }\end{array}$ & $\begin{array}{l}\text { One semantic differential item: } \\
\bullet \quad \text { D'ECO is totally irresponsible (responsible) toward } \\
\text { the environment }\end{array}$ & - \\
\hline $\begin{array}{l}\text { Newspaper's } \\
\text { credibility } \\
\text { (manipulation check) }\end{array}$ & $\begin{array}{l}\text { One semantic differential item: } \\
\bullet \quad \text { According to you, this information is totally credible } \\
\text { (not credible at all) }\end{array}$ & - \\
\hline
\end{tabular}

